\title{
ANALISIS ANTARMUKA WEBSITE POLITEKNIK LP3I MENGGUNAKAN KANSEI ENGINEERING
}

\author{
Rudi Hartono, Dede Rizal Nursamsi \\ Program Studi Magister Sistem Informasi, STMIK LIKMI Bandung \\ Jl. Ir. H. Juanda No.96, Kota Bandung \\ kangrudi17@gmail.com, rizaladityal@gmail.com
}

\begin{abstract}
Website in LP3I an important role in providing good information about the activities of the university. This research attempts to develop a university website based on Kansei Engineering. Kansei Engineering is used in this research to analyze psychological aspects related to the website of LP3I and recommend the appearance of the user interface of the website for LP3I. This research produces 15 main Kansei Words, 5 specimens related to the university, and recommends 13 main design elements.
\end{abstract}

Keywords - Kansei Engineering, Website, Aspek Psikologis, Kansei Word.

\begin{abstract}
Abstrak - Website di LP3I berperan penting dalam memberikan kemudahan bagi masyarakat tentang informasi kegiatan dan pendaftaran kampus. Penelitian ini bertujuan untuk menganalisi website kampus untuk memberikan pelayanan informasi yang lebih baik. Kansei Engineering digunakan dalam penelitian ini untuk menganalisis aspek psikologis terkait rancangan website LP3I sehingga bisa memberikan rekomendasi tampilan antarmuka website kampus yang lebih baik. Analisis tentang aspek psikologis menggunakan multivariate menghasilkan 15 Kansei Word, 5 spesimen yang berhasil diidentifikasi. Sedangkan, sebagai rekomendasi perancangan antarmuka website kampusnya dihasilkan 13 elemen desain.
\end{abstract}

Kata kunci - Kansei Engineering, Webiste, Aspek Psikologis dan Kansei Word.

\section{PENDAHULUAN}

Pada saat ini, instansi pemerintah, swasta maupun pendidikan sudah mempunyai website untuk memperkenalkan tentang informasi profilenya. Salah satunya perguruan tinggi yaitu Politeknik LP3I merupakan salah satu instansi pendidikan perguruan tinggi swasta, yang terdapat di kota Jakarta, yang mengelola website untuk memperkenalkan tentang profile, kegiatan-kegiatan apa saja, layanan-layanan yang terdapat di kampus tersebut. Politeknik LP3I mempunyai website yang beralamatkan di www.lp3i.ac.id.

Namun perlu dianalisis apakah website dari segi antarmuka sudah menarik perhatian pengunjung dan mendorong calon pengunjung lain untuk mengunjungi website tersebut. Maka dari itu perlunya proses investigasi serta analisis sehingga dapat didesain kembali website. Dalam penelitian ini, metode yang digunakan adalah Kensei Engineering (KE), merupakan salah satu teknologi yang berorientasi pada konsumen yang melibatkan pengguna produk dalam menghasilkan persyaratan desain untuk megembangkan produk yang disesuaikan dengan reaksi penggunanya. Sehingga dapat memberikan masukan untuk melakukan perbaikan terutama antarmuka dari website agar mendorong pengunjung untuk mengunjunginya.

\section{A. Kansei}

"Kansei: Sensitivity of a sensory organ where sensation or perception takes place in answer to stimuli from the external world". Kansei dapat dipahami sebagai kesan subjektif seseorang terhadap sekitarnya yang bisa ditangkap melalui panca indera. Kansei melibatkan kepekaan, sensibilitas, perasaan dan emosi onal yang diharmoniskan melalui lima penginderaan yaitu penglihatan (vision), pendengaran (hearing), penciuman (smell), perasaan (taste), dan perabaan (skin sensation). Istilah Kansei diterjemahkan ke dalam sebuah metode rekayasa sehingga menjadi Kansei Engineering. Metode ini pertama kali diperkenalkan oleh Mitsuo Nagamachi sebagai metode rekayasa yang baru dalam membantu proses desain dan pengembangan produk industri yang berorientasi perasaan manusia[1].

\section{B. Kansei Engineering $(K E)$}

Kansei Engineering dalam rekayasa aspek emosional dalam desain antarmuka sistem informasi berbasis web. Kansei Engineering, yang didasarkan pada disiplin matematika, statistik, psikologi dan rekayasa, ditemukan oleh Profesor Mitsuo Nagamachi dari Hirosima University di tahun 1970-an, untuk memungkinkan pengukuran aspek emosional konsumen terhadap suatu produk, dan menghubungkan hasilnya untuk elemen desain produk[1].

Dalam pembuatan sebuah produk, seringkali terpusat pada objektivitas pribadi mengenai desain produk tersebut, tanpa menghiraukan apa keinginan dari pengguna. Sehingga berpengaruh pada tingkat penjualan maupun tingkat kemauan pemakaian dari produk. Kansei Engineering : "Kansei Engineering is 
a technology that combines kansei and Engineering realms to assimilate human Kansei into product design targeting to engineer the 11 production of goods and consumer will enjoy and satisfy with" [2].

\section{Skala Semantic Differential}

Skala Semantic Differential (SD) sejak pertama kali diperkenalkan oleh Osgood dalam melakukan survey perilaku, sampai saat ini telah banyak digunakan dalam pengumpulan data berbasis kuesioner. Skala SD didasarkan pada skala likert yang pertama kali ditemukan oleh seorang ahli psikolog bernama Rensis Likert [3].

Ada beberapa ukuran atau poin dalam penggunaan skala ini dari mulai 5 poin sampai dengan 11 poin. Tetapi, berdasarkan hasil penelitian diketahui bahwa skala SD dengan 5 poin saja dianggap sangat cukup mewakili dalam penilaian suatu keputusan. Skala 5 poin menjadi standar skala $\mathrm{SD}$, sehingga menjadi paling banyak digunakan dalam pengambilan data kuesioner [4].

\section{METODE PENELITIAN}

Metodologi yang digunakan untuk pengembangan interface website LP3I mengadopsi KEPack untuk menghasilkan perbaikan website yang sesuai dengan kebutuhan pengunjung. Berikut langkah langkah dalam pengembanan dan analisisnya :

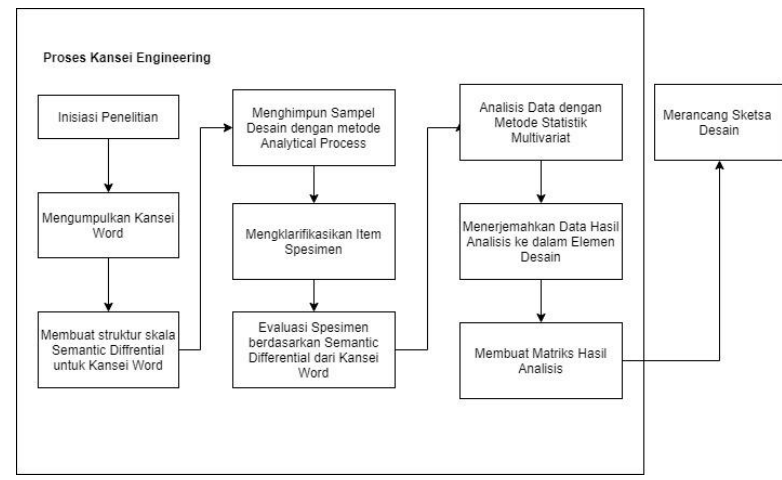

Gambar 1. Metodologi Penelitian

\section{Inisiasi Penelitian}

Pada tahap awal proses ini dimana tempat dan objek penelitian serta teknik Kansei yang akan dilakukan. Dalam penelitian yang ini yang di teliti adalah website politeknik LP3I.

2. Mengumpulkan dan Menghimpun Kansei Word Kansei Word yang digunakan diperoleh dari beberapa referensi atau literature terkait yang berkaitan dengan tampilan antarmuka website akan ditentukan.

3. Membuat Semantic Differential

Penyusunan skala Semantic Differential dengan Kansei Word yang ada dengan menggunakan tujuh skala Semantic Differential.
4. Menghimpun Sample Desain (Spesimen)

Penelitian ini menggunakan beberapa kandidat spesimen website dari hasil pencarian Google. Beberapa website terkait yang terkumpul kemudian akan diseleksi sehingga akan terpilih beberapa kandidaat yang bisa dijadikan sebagai spesimen dalam penelitian ini, dan akan digunakan sebagai dasar pembuatan rekomendasi desain website yang baru dalam penelitian ini.

5. Mengklasifikasi Item Spesimen

Setelah mendapatkan spesimen yang valid, langkah selanjutnya adalah mengkasifikasikan spesimen tersebut berdasarkan kategori elemen desain.

6. Evaluasi Spesimen berdasarkan Semantic Differential dari Kansei Word Populasi pada penelitian ini adalah calon pengguna website

7. Analisis Data dengan Metode Statistik Multivariat

Data yang sudah didapatkan dari tahap sebelumnya akan diolah menggunakan metode statistik multivariat. Analisis statistik yang akan digunakan adalah Coefficient Correlation Analysis, Principal Component Analysis dan Factor Analysis.

8. Menerjemahkan Data Hasil Analisis ke dalam Elemen Desain

Tahap ini masih berkaitan dengan tahapan sebelumnya yaitu mengolah data statistik ke dalam elemen desain menggunakan perhitungan analisis statistik Partial Least Square.

9. Membuat Matriks Hasil Analisis.

Sebagai tahap terakhir setelah melakukan analisis statistik adalah membuat matriks berdasarkan hasil analisis pada tahapan sebelumnya berupa matriks yang berisi kriteria usulan desain.

\section{HASIL ANALISIS DAN PEMBAHASAN}

Dari penelitian yang telah dilakukan maka dalam tahapan nya adalah sebagai berikut:

\section{A. Inisiasi Penelitian}

Kansei Engineering Type I (KEPack) digunakan dalam analisis penelitian ini adalah Website Portal sedangkan objek penelitiannya adalah Mahasiswa dengan jumlah partisipan yang terlibat sebanyak 30 orang dengan jumlah Kansei Words yang digunakan sebanyak adalah 15 kata, dan dan melibatkan sampel desain (spesimen) sebanyak lima spesimen.

\section{B. Kansei Word yang digunakan}

Daftar Kansei Words yang telah dihimpun dapat terlihat seperti table berikut : 
Tabel 1. Daftar Kansei Word

\begin{tabular}{|c|c|c|c|c|c|}
\hline No & $\begin{array}{c}\text { Kansei } \\
\text { Word }\end{array}$ & No & $\begin{array}{c}\text { Kansei } \\
\text { Word }\end{array}$ & No & $\begin{array}{c}\text { Kansei } \\
\text { Word }\end{array}$ \\
\hline 1 & Dinamis & 6 & Lembut & 11 & Profesional \\
\hline 2 & Informatif & 7 & Menarik & 12 & Bersemangat \\
\hline 3 & Keren & 8 & Futuristik & 13 & Nyaman \\
\hline 4 & Sederhana & 9 & Unik & 14 & Seimbang \\
\hline 5 & $\begin{array}{c}\text { Penuh } \\
\text { Warna }\end{array}$ & 10 & Rapi & 15 & $\begin{array}{c}\text { Kekanak- } \\
\text { kanakan }\end{array}$ \\
\hline
\end{tabular}

Dari tabel 1 diatas Kansei Words yang akan dihimpun harus merepresentasikan karakteristik dari website sehingga dapat mewakili emosi user terhadap spesimen.

\section{Semantic Differential (SD) Scale untuk Kanse Words (Kuesioner)}

Kansei Word yang telah diseleksi yang merepresentasikan karakteristik dari website, kemudian disusun dengan skala SD menggunakan 5 skor penilaian

\section{Menghimpun (Specimen)}

Dari beberapa website yang dijadikan perbandingan, maka ditentukan sebanyak 5 spesimen interface website yang memiliki karakteristik berbedabeda berdasarkan tema tampilan, pewarnaan dan struktur penempatan menu. Perbandingan ini untuk menghasilkan desain antarmuka yang diharapkan oleh pengguna.

Tabel 2. Daftar Specimen Website

\begin{tabular}{|c|c|c|}
\hline No & Nama Intansi & Url Web \\
\hline 1 & $\begin{array}{c}\text { Universitas } \\
\text { Indonesia }\end{array}$ & https://www.ui.ac.id/ \\
\hline 2 & $\begin{array}{c}\text { Politeknik } \\
\text { Bandung }\end{array}$ & https://www.polban.ac.id/ \\
\hline 3 & $\begin{array}{c}\text { Politeknik } \\
\text { Manufaktur } \\
\text { Bandung }\end{array}$ & https://polman-bandung.ac.id/ \\
\hline 4 & $\begin{array}{c}\text { Universitas } \\
\text { BSI }\end{array}$ & https://www.bsi.ac.id/ \\
\hline 5 & $\begin{array}{c}\text { Politeknik } \\
\text { LP3I }\end{array}$ & https://www.lp3i.ac.id/ \\
\hline
\end{tabular}

\section{E. Klasifikasi Elemen Desain}

Untuk memudahkan dalam pengelompokan spesimen yang berhasil dipilih, kemudian dalam proses penelitian selanjutnya adalah menguraikan hingga bagian terkecil elemen-elemen desain spesimen ke dalam sebuah matriks elemen desain yakni page body, header, top menu, left menu, right menu, main dan footer.

\section{F. Evaluasi Penelitian Berdasarkan Semantic Differential dari Kansei Word}

Hasil dari proses pengolahan data kuesioner yang kemudian direkap untuk menjadi sumber data agar dapat di proses ke dalam Multivariate statistical of analysis. Hasil rekap data kuesioner diakumulasikan dan dirata-ratakan secara manual dengan Microsoft Excel. Hasil rata-rata kuesioener ini digambarkan dalam bentuk gambar grafik sebagai berikut :

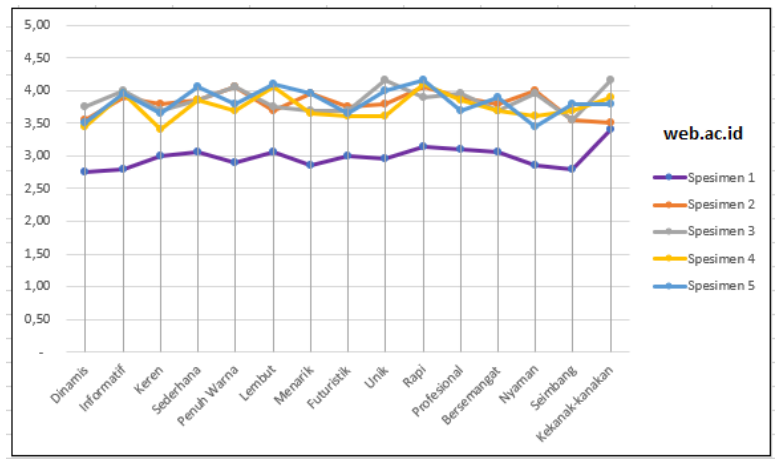

Gambar 2. Grafik Kuesioner

\section{G. Statistik Analisis Multivariat}

Tahapan ini untuk menganalisis penghitungan statisik menggunakan metode multivariat. Dari sejumlah data rata-rata yang di terima dari tahapan sebelumnya lalu kemudian diolah menjadi data untuk menentuak konsep emosi dari partisipan dengan metode statistik sebagai berikut ini:

\section{Coeffisien Corelation Analysis (CCA)}

untuk mengetahui korelasi antar Kansei Word atau yang selanjutnya disebut dengan emotion, dimaksudkan untuk mendalami dan mengetahui sejauh mana kedekatan hubungan antar tiap emosi (Kansei Word).

\section{Tabel 3 Hasil Anlisis CCA}

\begin{tabular}{|l|l|l|l|l|l|}
\hline Variables & Dinamis & Informatif & Keren & Sederhana & $\ldots$ \\
\hline Dinamis & 1 & & & & \\
\hline Informatif & 0,979 & 1 & & & \\
\hline Keren & 0,721 & 0,542 & 1 & & \\
\hline Sederhana & 0,707 & 0,512 & 0,321 & 1 & \\
\hline$\ldots$ & & & & & \\
\hline
\end{tabular}

Dilihat dari (CCA) Seluruh Partisipan, maka dapat terlihat bagaimana hubungan atau korelasi emosi antar Kansei Word dimana memiliki dua hubungan yaitu hubungan kuat dan hubungan yang lemah. Hubungan yang kuat ditandai dengan dengan nilai yang lebih tinggi dari nilai Kansei Word yang lain yaitu mendekati nilai 1 , dan hubungan yang lemah ditandai dengan nilai mendekati nilai "nol" atau $(<0,3)$. 
Beberapa emotion menunjukkan nilai tingkatan keberpengaruhan, seperti "Dinamis" dengan "Informatif" yang memiliki keterikatan kuat sebesar 0.979 atau memiliki pengaruh kuat, sama halnya antara "Futuristik" dengan "Informatif" yang memiliki pengaruh sebesar 0.542 .

\section{Principal Component Analysis (PCA).}

Principal Component Analysis atau PCA adalah metode statistik yang digunakan untuk mengompresi 15 emosi ke sumbu dua atau tiga yang lebih kecil. Struktur emosi dapat didefinisikan oleh analisis. Kemudian, menghasilkan 15 faktor atau dipanggil dengan Principal Component (PC) yang ditunjukkan pada Tabel 4.

Table 4 Principal Component Score

\begin{tabular}{|c|c|c|c|c|c|}
\hline & PC1 & PC2 & PC3 & $\cdots$ & PC15 \\
\hline Eigenvalue & 11,657 & 4,432 & 2,112 & $\cdots$ & \\
\hline $\begin{array}{c}\text { Variability } \\
(\%)\end{array}$ & 62,625 & 15,302 & 11,644 & $\cdots$ & \\
\hline $\begin{array}{c}\text { Cumulative } \\
(\%)\end{array}$ & 62,625 & 86,126 & 89,015 & $\cdots$ & 100,000 \\
\hline
\end{tabular}

Pada Tabel 4 menunjukkan skor nilai eigen atau varians dan variabilitas untuk setiap PC1 ke PC15. Skor nilai eigen masing-masing PC1 dan PC2 adalah 11,657 dan 4,432 dengan tingkat variabilitas 62,625\% dan $15,302 \%$. Pada baris Kumulatif, PC1 dan PC2 menunjukkan $86,126 \%$ dari total varian. Ini berarti PC1 dan PC2 telah diwakili dari analisis data dan memiliki pengaruh untuk emosi. Selanjutnya, jika diamati bahwa PC3 ke PC15 memiliki skor nilai eigen yang lebih rendah dan persentase variabilitas tidak signifikan, karena PC1 dan PC2 telah mewakili lebih dari $80 \%$ dari total varian, sehingga PC3 ke PC15 dapat diabaikan dan fokus pada PC1 dan PC2 untuk analisis selanjutnya.

Hasil Principal Component (PC) tersebut kemudian di terjemahkan ke dalam scree plot seperti grafik di bawah ini :

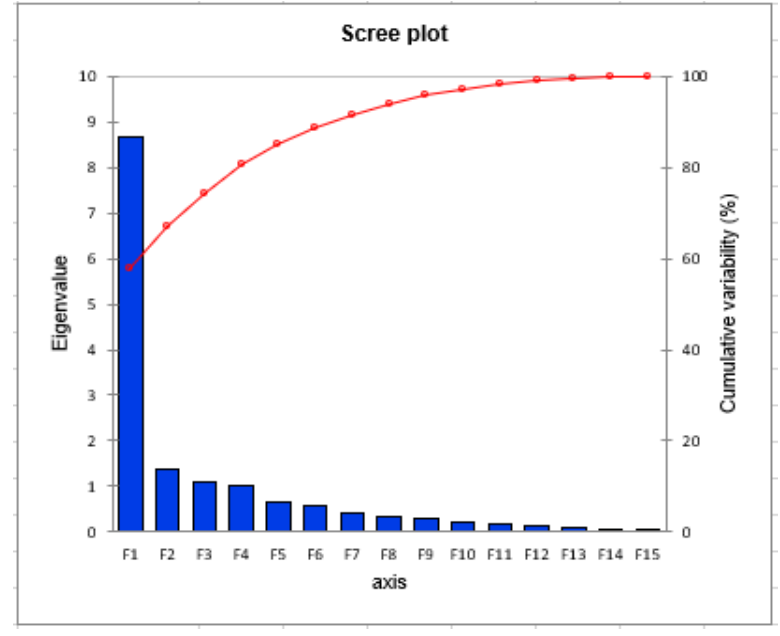

Gambar 3. Scree Plot PC

Gambar Scree Plot tersebut merupakan hasil dari table nilai Principal Component (PC). Data-data yang digunakan adalah nilai eiguvalue, nilai variability dan nilai cumulative. Grafik pada Gambar 3 menggambarkan bahwa F1 dan F2 dapat mewakili dalam penunjukan struktur emosi pengguna.

Dalam penelitian ini PC Loading terlibat untuk mengeksplorasi distribusi emosi ke sumbu, sehingga konsep emosi dapat didefinisikan yang memiliki pengaruh terhadap spesimen. Tiga tahapan analisis PCA ini menggunakan varimax rotation, dikarenakan hasil yang diberikan lebih akurat dan baik untuk konsep design. Tahapan tersebut sebagai berikut :

1. PC Loading, berguna untuk mengetahui sebaran emotion menunjukan seberapa beser evaluasi emosi yang berpengaruh dalam spesimen.

2. PC Score, digunakan untuk menentukan hubungan antara emosi dengan spesimen website.

3. PC Vector, digunakan untuk memvisualisasi arah dan kekuatan emosi atas struktur emosi, dan bagaimana menentukan konsep baru website. Gambar 4 merupakan hasil dari Loading F1 dan F2. Dapat dilihat pada gambar berikut : 


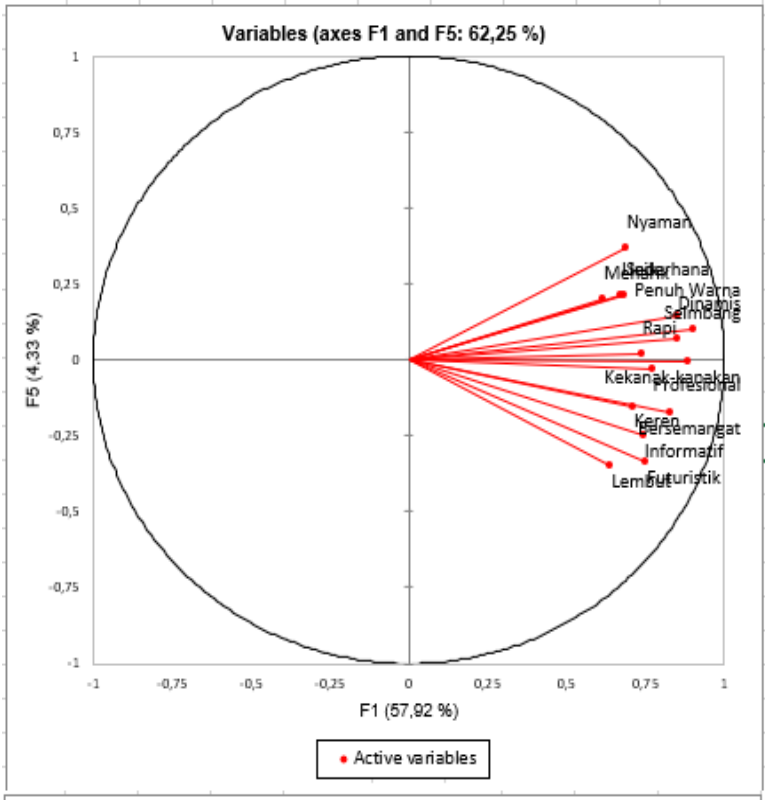

Gambar 4. Hasil PC Loading

\section{Factor Analisis}

Analisis ini untuk memperinci dan memperkuat hasil PCA serta menemukan factor yang signifikan dari Kansei . Data rekapitulasi rata-rata digunakan sebagai bahan analisis FA dengan menggunakan varimax rotation untuk memperoleh nilai yang lebih akurat.

\section{Tabel 5. Daftar Kansei Word}

\begin{tabular}{|c|c|c|}
\hline Faktor & F1 & F2 \\
\hline Variability (\%) & 62,625 & 15,302 \\
\hline Cumulative (\%) & 62,625 & 86,126 \\
\hline
\end{tabular}

Tabel 5. menampilkan 2 Faktor yang dianggap memiliki pengaruh dominan terhadap factor emosi pengguna. Sama seperti PCA, FA terdapat dua nilai dengan Variability dan Cumulative. F1 dan F2 ini mewakili dalam analisis website. Tabel korelasi antar factor dengan emosi setelah varimax rotation di tunjukan pada table dibawah ini :

Tabel 6. Korelasi Antara Faktor dengan Emosi

\begin{tabular}{|c|c|c|}
\hline Kansei Word & F1 & F2 \\
\hline Dinamis & 0,931 & 0,122 \\
\hline Informatif & 0,822 & $-0,176$ \\
\hline Keren & 0,751 & $-0,092$ \\
\hline Sederhana & 0,687 & 0,231 \\
\hline Penuh Warna & 0,601 & $-0,087$ \\
\hline$\ldots$ & $\ldots$ & $\ldots$ \\
\hline
\end{tabular}

Nilai dari hasil analisis faktor yang disajikan dalam table 6. Kemudain variabel yang mempunyai nilai tertinggi akan menjadi acuan dalam penilaian website korelasi emosi kansei word memiliki hubungan kuat, sedangkan variable nilai kecil dan atau negative menunjukan korelasi emosi Kansei Word tersebut memiliki hubungan yang lemah.

Berdasarkan hasil penilaian desain antar muka website memiliki konsep emosi "Dinamis", "Informatif", "Keren", "Sederhana”, "Penuhwarna", yang memiliki nilai lebih dari 0,7 akan dijadikan acuan untuk penilaian desain antar muka website karena dianggap mempunyai nilai tinggi.

Konsep emosi "Dinamis" memiliki nilai tinggi pada faktor satu, sedangkan konsep emosi "Kekanak - kanakan" memiliki nilai tertinggi di faktor dua tetapi nilai koefision terlalu kecil sehingga dapat dianggap tidak berpengaruh. Dengan demikian hanya dengan konsep "Dinamis" yang akan dijadikan acuan dalam penilaian perancangan antarmuka website.

\section{KESIMPULAN}

Analisis desain interface Website dilakukan dengan pendekatan Kansei Engineering serta melibatkan faktor psikologis dan emotion maka dapat diambil kesimpulan sebagai berikut :

1. Lima konsep emotion berpengaruh kuat dalam design anatarmuka website ini adalah: Dinamis, Informatif, Keren, Sederhana, dan Penuh Warna.

2. Untuk pengembangan selanjutnya yang perlu diperhatikan adalah konsep dinamis serta perlu melibatkan partisipan yang memiliki pengetahuan mendalam dalam produk yang diteliti dalam penerapan Kansei Engineering. 


\section{DAFTAR PUSTAKA}

[1] Lokman., A.M., Noor, L.M., Nagamachi, M., Kansei Engineering : A Study on Perception of Online Clothing Website, Linkoping University Electronic Press, Swedia, 2006.

[2] Lokman., A.M., Noor, L.M., Kansei Engineering Concept in E-Commerce Website, Proceedings of the International Conference on Kansei Engineering and Intelligent Systems (KEIS '06), Aizu, Japan, 2006.

[3] Hadiana, Ana and M.Lokman, Anitawati, Kansei Evaluation In Open Source Elearning System, 2015.

[4] Lokman, A.M, \& Kamaruddin, K.A.. Kansei Affinity Cluster for Affective Product Design, 38-43, 2010. 